\title{
PHOTO NOTES
}

\section{BREWER'S BLACKBIRDS USE ARTIFICIAL NEST SITE}

\section{LORNE SCOTT, Box 995, Indian Head, SK S0G 2K0}

For the past several years, a few pairs of Brewer's Blackbirds Euphagus cyanocephalus have nested in my yard on old machinery that is not in use. Snowberry and tall grass are usually growing among the equipment. Often the nests are located under an overhang that helps to keep rain off the nest

Early in the spring of 2012 I built a shelf about eight inches square with a roof and placed it under the eve of a wooden grain bin, thinking I might attract robins to nest.

On 30 June 2012, I observed a female
Brewer's Blackbird sitting on a loosely constructed nest of plant material in the open-ended shelf on the grain bin. When I checked the contents in the nest in mid July there were four young. I banded the young on July 18, 2012 and they fledged successfully.

I have found that Brewer's Blackbirds will sometimes return to the same nest site in following years, so it will be interesting to see if they will use the artificial nest site in 2013.

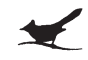

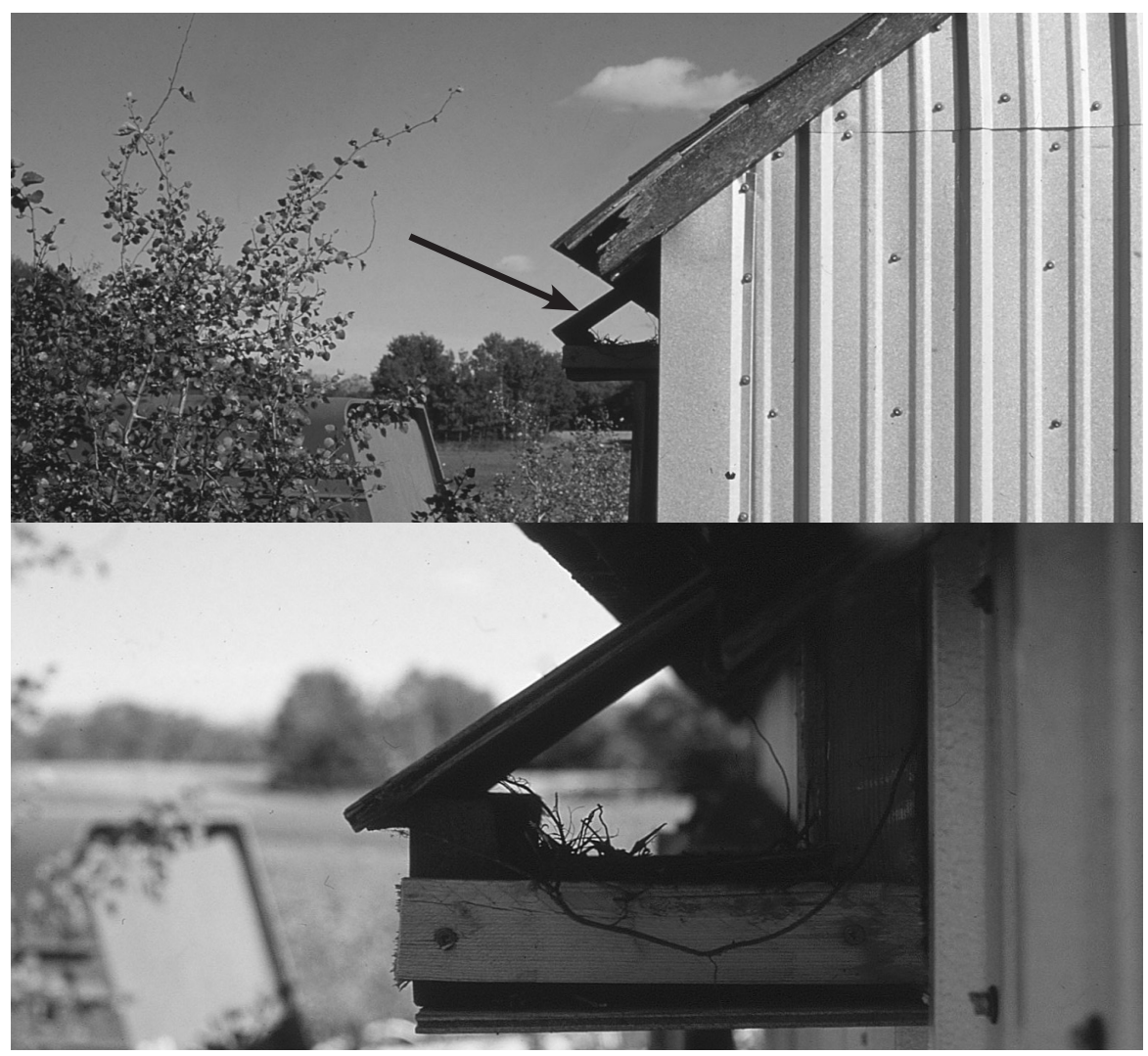

